\title{
Orígenes y desarrollo de las televisiones culturales en Europa. Una comparación entre la Segunda Cadena de TVE, BBC-2 y RTP-2 (1966-1975)
}

Origins and Development of Cultural Television in Europe. A Comparison between TVE'S Second Channel, BBC-2 and RTP-2 (1966-1975)

\section{JuAN MaRTín Quevedo}

Universidad Rey Juan Carlos

juan.martin.quevedo@urjc.es

\section{(iD}

NuRIA NAVARRO SIERRA

Universidad Rey Juan Carlos

nuria.navarro.sierra@urjc.es

Facultad de Ciencias de la Comunicación

Departamento de Ciencias de la Comunicación y Sociología

Campus de Fuenlabrada

Camino del Molino, 5 ,

28942 Fuenlabrada (Madrid) (España)

\section{Gema María Gómez RodRíguez}

Universidad Complutense de Madrid

Facultad de Ciencias de la Información

Avda. Complutense, 3

28040 Madrid (España)

gema.gomezn@gmail.com

Resumen: La aparición de las segundas cadenas de televisión a mediados de los 60 propició un escenario en Europa con grandes diferencias, en el que se distinguía, a grandes rasgos, un modelo liberal, habitual en el norte del continente, y un modelo mediterráneo, más dependiente del Estado. Sin embargo, ambos modelos, pese a partir de situaciones legales y económicas muy diferentes, tuvieron algunos problemas comunes, como la dificultad de lograr despertar el interés de la población hacia una programación más cultural. Esta investigación se propone poner esta situación de manifiesto a través de un análisis comparativo de la Segunda Cadena de TVE con la BBC-2, paradigma de las televisiones públicas liberales del norte de Europa, y la portuguesa RTP-2, de un régimen similar al español.

Palabras clave: Televisión. BBC. RTP. TVE. Historia de los medios.

Abstract: The apparition of the television's second channels in the sixties caused a scenario in Europe with many differences, with roughly two main models: a liberal model, frequent in Northern Europe, and a Mediterranean model, in which televisions were more State-dependent. However, both models had common problems, such as attracting people's interest about a more cultural programming. This research aims to show this situation through a comparative analysis between TVE's Second Channel and BBC-2, paradigm for public service televisions, and the Portuguese RTP-2, also a public broadcaster from an authoritarian regime.

Keywords: Television. BBC. RTP. TVE. Media History 


\section{INTRODUCCIÓN}

La ola expansionista de la posguerra, el baby boom y los avances sociales que la acompañaron propiciaron el surgimiento de una moderna sociedad de consumo en muchos países europeos', algunos de los cuales, como era el caso español, provenían de una etapa de aislacionismo y carestía. Esta nueva forma de sociedad estuvo inextricablemente ligada a la televisión, un medio moderno y capaz de crear una «cultura común»; en palabras de Raymond Williams: un conjunto de actitudes, deseos y costumbres compartidos por el conjunto de las sociedades occidentales ${ }^{2}$. En el caso español, TVE se transformó desde un medio de influencia reducida, que solo se recibía en Madrid y Barcelona, y que solo era capaz de emitir unas pocas horas al día, con una programación de bajo presupuesto, a un medio de comunicación de masas con una destacada presencia en la vida de los españoles ${ }^{3}$. Precisamente, su nacimiento fue dilatado por el gobierno franquista por considerarlo un medio peligroso, pero, no obstante, a la vez necesario para dejar que España siguiera rezagada con respecto al resto de países europeos del momento ${ }^{4}$. El cambio fue lento y exigió una modificación de la programación para equipararse al modelo de otras televisiones europeas, como la BBC o la francesa ORTF, por señalar dos referentes. El medio se concebía como un instrumento dirigido por los estados, pero con tácticas comerciales en su programación, ya que la publicidad era una gran fuente de financiación e ingresos que permitió rápidamente la expansión de la televisión ${ }^{5}$. El despliegue de medios y la presentación de sus producciones a certámenes internacionales y la obten-

\footnotetext{
I Como señala Judt, 2016, pp. 495 y ss., los salarios se duplicaron en países como Reino Unido, y aumentaron todavía más en otros, mientras que se multiplicaban las grandes superficies. En Francia, por ejemplo, se pasó de 49 supermercados a principios de los 60 a 1833 en solo 10 años, así como el auge de los electrodomésticos, entre los que cabe destacar el televisor. La extensión del medio fue desigual: si en 1953 había más de 10 millones de televisores en Reino Unido, en países como Alemania apenas se llegaba a los 200000 . De hecho, en Alemania Occidental el porcentaje de hogares con al menos una televisión pasó del $4 \%$ en 1956 al $77 \%$ en 1970 (Wasserstein, 2007, p. 539). Sin embargo, la publicidad y el crecimiento económico fomentaron el auge del medio, y en 1970 ya se había alcanzado un promedio de un televisor por cada cuatro personas en Europa occidental, y dos de cada tres familias contaban con el dispositivo (Judt, 2016, p. 506). Sobre la relación entre medios, poder y formación de la sociedad de consumo, Spring, 2003. También sobre el nacimiento de esta relación en los inicios del medio, aunque referido al caso estadounidense, Craig, 1993 y Boddy, 1993.

2 Maase, 2016, pp. 247 y ss.

3 Un proceso que abarcaría a todos los medios de la época, especialmente la prensa (Humanes y Martínez Nicolás, 2014-2015, pp. 79-89) y la radio (Faus Belau, 1995; García Gil, Gómez García y Reguero Sanz, 2018, Pp. $1179-1210)$.

${ }^{4}$ Palacio, 2002, pp. 79-80.

${ }^{5}$ Rueda Laffond y Coronado Ruiz, 2010, p. 172.
} 
ción de premios en los mismos formaron también parte de este proceso. También parte de ese crecimiento en la capacidad técnica y artística y de las infraestructuras fue la creación en 1966 de la Segunda Cadena, también llamada coloquialmente el UHF.

La Segunda Cadena de TVE presentaba particularidades que la diferenciaban de la Primera: su programación tenía carácter minoritario y experimental y apostaba, principalmente, por la elevación del nivel cultural de los espectadores. Muchos de estos rasgos se debían a que se dirigían a públicos distintos y con unas estrategias de programación diferenciadas: una audiencia generalista en el caso de TVEI, y una minoritaria y urbana en el de TVE2. No obstante, el canal español también desarrolló una serie de peculiaridades que lo dotaron de una identidad propia respecto a las otras segundas cadenas europeas que estaban surgiendo en el momento, con las que presentaba tantas diferencias como similitudes.

Las segundas cadenas empezaron a proliferar en Europa occidental a mediados de los años sesenta. La pionera fue RAI2, que inauguró sus emisiones oficiales en I96I, y pocos años después le sucedieron el resto de los países cercanos a España: RTF2 (hoy France 2) y la alemana ZDF en 1963, BBC2 en abril de 1964 y RTP2 en 1968. No obstante, aunque estas cadenas surgieron de forma casi simultánea por una cuestión tecnológica, el debate que rodeó su creación en muchos de estos países puso de manifiesto dos aspectos: por un lado, la reticencia de los estados a permitir la creación de nuevos canales de gestión privada -la lucha por el control de la ZDF enfrentó a los länder y a los editores de prensa durante años, y llegó tanto al Bundestag como al Tribunal Constitucional, por ejemplo6; y lo mismo ocurrió, ya en los años 80 , con el recurso de amparo de Antena 3 ante el Tribunal Constitucional, que en 1982 impidió al grupo crear una televisión, lo que les obligó a transformarse en una radio a la espera de un cambio legislativo ${ }^{7}-y$, por otro, la preocupación por mantener una lógica de servicio público en las recién creadas segundas cadenas.

Este proceso, además, se enmarca en una serie de cambios más amplios en el sistema televisivo internacional. Por un lado, es clave el desarrollo de las retransmisiones en color, que exigían la emisión en UHF (Ultra High Frequency), frente a la televisión anterior, que lo hacía en VHF (Very High Frequency). El UHF abría la posibilidad de tener un segundo canal que emitiera en color, como se verá, pero exigía también el desarrollo de una red paralela - tanto en infraestructura como en el parque televisivo nacional- que permitiera en el futuro hacer la transición a una televisión completamente en color.

\footnotetext{
${ }^{6}$ Manfredi, 2008, pp. 35 y ss.

${ }^{7}$ Barrera, 2015, p. 177. 
Por otro lado, la internacionalización de la televisión hizo que esta dejara de trascender los límites de los países, y necesitara enmarcarse en unos estándares consensuados, tanto en aras de la colaboración como del prestigio internacional. En este proceso fue clave el desarrollo de servicios adaptados a la televisión por parte de las grandes agencias de noticias, pero también, a partir de principios de los años 60, el de las redes de satélites que unían los diversos países y continentes, como INTELSAT en Occidente o la red INTERSPUTNIK en el bloque soviético. A esto se sumarían agencias de colaboración específicamente europeas, como la creación de la Unión Europea de Radiodifusión (UER) en 1952 e Intervisión, que aglutinaría a los países del Este a partir de 1960.

\section{MÉTODOS DE DEFINICIÓN DEL CRISOL DE LAS TELEVISIONES EUROPEAS}

La manera en que se configuró la televisión en Europa implicó unos rasgos comunes y un desarrollo relativamente paralelo, incluso teniendo en cuenta que hubo dos grupos claramente delimitados: los que tuvieron emisiones antes de la guerra, aunque fueran experimentales, $y$ aquellos que se incorporaron a partir de los años cincuenta ${ }^{9}$. Sin embargo, cada una de estas cadenas tenía sus propias características, derivadas tanto de su historia reciente como de su sistema político y del equilibrio de poder entre los poderes fácticos que dominaban la sociedad. Es difícil establecer unos modelos claros porque, debido a estas diferencias, a veces parecen estar formados más por excepciones que por partes de un mismo conjunto, $y$ en cualquier caso existen muchos criterios posibles para agruparlos, como muestra la siguiente tabla:

\footnotetext{
8 Un buen relato de todo este proceso puede encontrase en Faus Belau, 1995; Rings, 1964; y Noam, 1991.

9 Sobre esto, ver una comparación entre distintos países en Tracey, 1992. Para una visión más técnica, centrada en cómo condicionó a las emisiones de posguerra el haber contado con un servicio experimental previo, es útil referirse al caso británico, tanto desde la perspectiva organizacional, Briggs, 1995a, como la de las dificultades del día a día para desarrollar una programación que tenía mucho de improvisada y de hacer lo que se podía más que lo que estaba planeado, Jacobs, 2000. Compárese con el caso español en Palacio, 1992; y, sobre todo, Ezcurra, 1974.
} 
Tabla I. Comparación entre las principales televisiones europeas Fuente: elaboración propia, a partir de datos de Silvey, 1974; Schulz, 1991, Ortiz, 2012, Noam, 1991, Martín Quevedo, 2015, Manfredi, 2008, Levy 1998 y Jeanneney, 2000

\begin{tabular}{c|c|c|c|c|c|c|c}
\hline \hline & $\begin{array}{c}\text { Comienzo } \\
\text { de las } \\
\text { emisiones } \\
\text { del primer } \\
\text { canal }\end{array}$ & $\begin{array}{c}\text { Comienzo } \\
\text { de las } \\
\text { emisiones } \\
\text { del } \\
\text { segundo } \\
\text { canal }\end{array}$ & Ámbito & Financiación & Gestión & $\begin{array}{c}\text { Programación } \\
\text { Primer canal }\end{array}$ & $\begin{array}{c}\text { Programación } \\
\text { Segundo } \\
\text { canal }\end{array}$ \\
\hline $\begin{array}{c}\text { BBC } \\
\text { (Reino } \\
\text { Unido) }\end{array}$ & 1934 & 1964 & Nacional & Canon & $\begin{array}{c}\text { Corporación } \\
\text { independiente }\end{array}$ & Generalista & $\begin{array}{c}\text { Generalista - } \\
\text { cultural }\end{array}$ \\
\hline $\begin{array}{c}\text { RTF } \\
\text { (Francia) }\end{array}$ & 1949 & 1963 & Nacional & $\begin{array}{c}\text { Canon (y } \\
\text { publicidad } \\
\text { limitada partir } \\
\text { de I968) }\end{array}$ & $\begin{array}{c}\text { Director } \\
\text { nombrado por } \\
\text { el Gobierno }\end{array}$ & Generalista & Generalista \\
\hline $\begin{array}{c}\text { ARD } \\
\text { (República } \\
\text { Federal de } \\
\text { Alemania) }\end{array}$ & 1954 & 1963 & Regional & $\begin{array}{c}\text { Canon } \\
\text { Director } \\
\text { nombrado por } \\
\text { un Consejo } \\
\text { (gobiernos } \\
\text { regionales y } \\
\text { sociedad civil) }\end{array}$ & Generalista & Generalista \\
\hline $\begin{array}{c}\text { RAI } \\
\text { (Italia) }\end{array}$ & 1954 & 1961 & Nacional & $\begin{array}{c}\text { Canon y } \\
\text { publicidad a } \\
\text { partir de 1957 } \\
\text { nombrado por } \\
\text { el Gobierno }\end{array}$ & Generalista & $\begin{array}{c}\text { Generalista con } \\
\text { algunos }\end{array}$ \\
\hline $\begin{array}{c}\text { RTP } \\
\text { (Portugal) }\end{array}$ & 1955 & 1968 & Nacional & $\begin{array}{c}\text { Presupuestos } \\
\text { del Estado y } \\
\text { publicidad } \\
\text { limitada }\end{array}$ & $\begin{array}{c}\text { Director } \\
\text { nombrado por } \\
\text { el Gobierno } \\
\text { minorías }\end{array}$ \\
\hline $\begin{array}{c}\text { TVE } \\
\text { (España) }\end{array}$ & 1956 & 1966 & Nacional & $\begin{array}{c}\text { Presupuestos } \\
\text { del Estado y } \\
\text { publicidad }\end{array}$ & $\begin{array}{c}\text { Director } \\
\text { nombrado por } \\
\text { el Gobierno }\end{array}$ & Generalista & $\begin{array}{c}\text { Generalista - } \\
\text { cultural (desde } \\
\text { I973) }\end{array}$ \\
\hline \hline
\end{tabular}

Así, por ejemplo, una posibilidad sería hablar de la politización del medio, entendida como el control político e informativo que los gobiernos pretendían ejercer a través de estos entes. En ese caso cabría hablar de dos modelos. Por un lado, el modelo liberal del norte de Europa, que incluiría los audiovisuales escandinavos - gestionados por una empresa pública, pero que gozaban de una enorme independencia-, así como el británico y el alemán, gestionados por corporaciones independientes, financiadas por un canon y auditadas periódicamente por el Estado. Por otro lado, el modelo mediterráneo, de corte estatal, conformado por los países del sur, tanto las democráticas Francia e Italia como las dictaduras española y portuguesa en el extremo más polarizado del espectro ${ }^{10}$.

$Y$, sin embargo, con ser este un criterio aparentemente claro, se encuentran en el mismo grupo televisiones muy diversas. En el primero, aparecen la BBC, una cadena fuertemente centralista en lo cultural, al menos hasta bien entrados los años cincuenta, y que coexistía con un canal comercial semi-independiente; la

\footnotetext{
10 Como ejemplo, véase el uso de consignas y de los recursos específicos de RTVE para la creación de una imagen de Franco como líder en García-Gómez, Martín-Quevedo y Quevedo-Redondo, 202I.
} 
ITV "I, con la alemana ARD, un monopolio del Estado fuertemente descentralizado y formado por los diversos audiovisuales de las regiones - y ni siquiera, en tanto que muchos de ellos corresponden a varios länder, pues sus áreas de influencia fueron delimitadas siguiendo las zonas de ocupación aliadas en la posguerra, anteriores a la formación de los gobiernos regionales-12. En el segundo grupo, la televisión francesa estaba fuertemente politizada, especialmente durante los gobiernos del general De Gaulle, lo que provocó el resentimiento del principal partido de la oposición, el PSF ${ }^{13}$. Y, sin embargo, tampoco se llegó al extremo de politización del sistema italiano, cuya estabilidad política dependía del pacto de gobierno entre los democratacristianos y los socialistas que, a su vez, tenía como principio el aislar al segundo partido, el comunista $\mathrm{PCl}$, de las ondas, lo que se plasmó en un reparto de las televisiones, con un primer canal para los democristianos, y un segundo para los socialistas. Ello derivó en un clima audiovisual y político muy enrarecido y un sistema público que se vio muy deteriorado cuando tuvo que enfrentarse a la competencia tras la liberalización ${ }^{14}$.

Más allá del marco legal, tampoco todos los canales públicos de un mismo país gozaron de la misma autonomía, en buena medida por una cuestión técnica -los segundos canales tardaron más en gozar de una cobertura nacional, por un lado, y el hecho de necesitar un receptor complementario, por otro- y por su programación generalmente más cultural, aspectos ambos que contribuyeron a que su audiencia frecuentemente fuera mucho menor que sus parientes mayores, por lo que los gobiernos tendieran a prestarles menor atención ${ }^{15}$. Además, más allá de la posible voluntad de control, no todos los gobiernos dispusieron de los mismos recursos para implementar estos mecanismos ${ }^{16}$. Ese fue el caso de la

1 Para una historia de la BBC desde sus orígenes, la fuente más completa es la monografía en cinco volúmenes de Asa Briggs: Briggs, 196I; Briggs, 1965; Briggs, 1970; Briggs, 1995a y Briggs, 1995b. Respecto a la ITV, la propia cadena patrocinó la publicación dedicada a su historia: Sendall, 1982; Sendall, 1983; Potter, 1989 y Potter, 1990

12 Para una visión más de conjunto de la televisión alemana, Schulz, 1991.

13 Una buena aproximación a la televisión francesa puede encontrarse en Emanuel, 1993; Levy, 1998, p.199212 ; y, Jeanneney, 1999.

${ }^{14}$ Hibberd, 200I, pp. 234.

${ }^{15}$ En algunos casos, esto coincidió con un aumento relativo de la independencia del audiovisual en su conjunto, como ocurrió en Francia con la creación, en 1964, de la ORTF (L'Office de Radiodifusion Télévision Française), tras el escándalo de la cobertura de la guerra de Argelia, que gozaba de una mayor autonomía que el modelo anterior, Manfredi, 2008, y Briggs y Burke, 2002. No obstante, su independencia siguió siendo muy relativa, o, como lo veía el ministro de Información francés en 1965, «en circunstancias normales no es razonable que la oposición se exprese tan a menudo como el gobierno. El gobierno tiene algo que decir, ya que gestiona los asuntos de la nación. La oposición solo puede criticar», Wasserstein, 2007, p. 540.

${ }^{16}$ En varios países los audiovisuales públicos sufrieron graves recortes presupuestarios, como en Canadá, Portugal o Reino Unido, lo que en ocasiones obligó a buscar fuentes alternativas de financiación. Fue el caso de la $B B C$, que hubo de establecer un canon adicional para acceder a las emisiones en color. Briggs y Burke, 2002, pp. 240 y ss. 
Segunda Cadena española, que en muchos sentidos tuvo mucho que ver en su autonomía con los estándares de un país democrático, a pesar de tratarse de la televisión de una dictadura, por cuanto sus principales limitaciones fueron más de índole económica que política ${ }^{17}$.

Precisamente, para poner de relieve estos rasgos se ha realizado una comparación entre la propia Segunda Cadena española y otros dos segundos canales: la BBC-2, por ejemplificar el canon de lo que se consideraba una televisión pública y el ejemplo a seguir por la mayoría de audiovisuales europeos, y por ser el audiovisual mejor documentado del modelo liberal, y la RTP-2 portuguesa, porque muestra una alternativa a cómo se podía haber orientado la Segunda Cadena en circunstancias muy similares, dados los paralelismos entre el régimen portugués y el español y su evolución política, y es también un ejemplo del modelo estatalista ${ }^{18}$. Para comparar ambos modelos apropiadamente, se han distinguido tres ejes a analizar: el eje organizativo - la estructura del canal, los recursos con que contaba y cómo fue evolucionando desde su puesta en marcha hasta el fin del período-, el eje programático — qué se emitía- y el eje de la recepción —audiencia y actitud para con ella-.

Para ello se ha recurrido a un análisis comparativo transnacional, en la línea de otras obras de análisis histórico de televisiones ${ }^{19}$. Tal como plantea Syvertsen ${ }^{20}$, a diferencia de un estudio de caso, que contempla muchas variables de un solo objeto, o del análisis de sondeo, que estudia pocas variables de muchos objetos, el análisis comparativo aborda un limitado número de casos, pero con una relativa amplitud de variables. Supera, así, la limitada posibilidad de universalización de un estudio de caso, mientras ofrece una mayor riqueza de resultados que un análisis de sondeo. Además, es útil para identificar y analizar los rasgos estructurales comunes, incluso los que no son explícitos, de objetos en

\footnotetext{
17 Por ejemplo, en los informativos, espacio especialmente susceptible a las limitaciones políticas, la Segunda Cadena gozó de una extraordinaria libertad, y sus condicionantes vinieron más bien por la falta de presupuesto. Esto obligó a dejar de emitirlo durante largos períodos de tiempo (Montero Díaz, Rubio Moraga, Antona Jimeno, Martín Quevedo, y Fernández Ramírez, 2014, p. 9-24; Martín Quevedo, 20I5; y Martín Quevedo, 2014, p.73-89). Una evolución bastante diferente a la que experimentó el primer canal en los mismos años (Zamora Martínez y Berrocal Gonzalo, 2019; Montero Díaz, 2018). De hecho, la evolución de ambas cadenas continuaría por las mismas líneas ya en democracia, con gobierno y oposición preocupados por las injerencias políticas en TVE-I, pero relegando la Segunda Cadena al olvido casi absoluto, tanto en lo presupuestario como en el debate político (Martín Quevedo, Antona Jimeno y Navarro Sierra, 2020; RegueroSanz, Berdón-Prieto, y García-Gil, 2020).

18 Ortiz Sobrino y López Vidales, 2012.

${ }^{19}$ Fickers y Johnson, 2010: I-I I; Martín Quevedo y Fernández Ramírez, 2020; Peruško y Čuvalo, 2014: I3I150.

20 Syvertsen, 1992.
} 
diferentes contextos, en tanto que plantea preguntas de investigación respecto a por qué ciertos rasgos varían con el contexto y otros no.

Por su parte, Lijphart apunta que el criterio fundamental en este tipo de análisis es la comparabilidad de los casos escogidos ${ }^{21}$. Esto es, que sean lo suficientemente diferentes como para que el análisis ofrezca resultados interesantes, pero lo bastante similares como para ser comparables. En ese sentido, los tres audiovisuales escogidos presentan, como se ha dicho, varios rasgos comunes fundamentales:

I. Son audiovisuales estatales europeos en régimen de monopolio o cuasimonopolio.

2. Pertenecen a países industrializados y desarrollados.

3. Existe un contexto cultural común entre todos ellos, aunque suficientemente diferenciado en sus especificidades nacionales.

4. Aunque Reino Unido era una democracia y España y Portugal estaban inmersas en dictaduras, en todos los casos eran regímenes estables y consolidados, que requerían, para el normal funcionamiento social, de apoyarse más en el consenso que en la coerción.

\section{RESULTADOS}

\section{I. El eje organizativo: de los buenos propósitos a las dificultades reales}

La puesta en marcha de una segunda cadena requería una inversión considerable por parte del Estado, y ello exigía una justificación clara de tal decisión. En la Europa continental no era complicado: se trataba de ofrecer una «competencia» a la primera cadena, o, más bien, un canal complementario que ofreciera la posibilidad de elegir para el espectador.

Este fue, por ejemplo, el caso alemán. En un afán por evitar que el Estado central volviera a tener la influencia de que había gozado durante el nazismo, los Aliados optaron por proponer un audiovisual basado en las regiones y bajo la autoridad de estas, en un modelo que huyera del tono doctrinal, más parecido al estadounidense que al de otros países europeos ${ }^{22}$. Por otra parte, también estu-

\footnotetext{
21 Lijphart, 197I, pp. 682-693.

22 Como planteó el general Alex Bishop, encargado del desarrollo de la radiodifusión en la Alemania ocupada ya en diciembre de 1945, la televisión en Alemania debía estar «en la línea de las transmisiones nacionales de la BBC [...]. Para cumplir su objetivo de mantener la audiencia y contribuir a crear una nueva tradición en la radiodifusión alemana, no debía tener un tono demasiado edificante, ni la información debía ser demasiado propagandística. Una excesiva atención a la reeducación política e histórica de los alemanes destruiría su credibilidad. [...] Una presentación demasiado abierta del punto de vista «del mundo» o «británico» del pasado reciente debería trasladarse por otros medios» (Tracey, 1992, pp. 165 y ss. Traducción propia).
} 
vieron de acuerdo en que la financiación y el régimen jurídico debían ser parecidos a los de la BBC y no una televisión comercial basada en la publicidad, inviable en un país devastado por la guerra mundial, por lo que el resultado final fue un híbrido entre las televisiones que hacían los anglosajones a ambos lados del Atlántico. De ahí que el segundo canal fuera propuesto en repetidas ocasiones por distintos partidos, empezando por el propio canciller Konrad Adenauer, y que lo difícil fuera ponerse de acuerdo en la naturaleza de este ${ }^{23}$. En Reino Unido, como se ha dicho anteriormente, el panorama era algo más complicado, pues la BBC ya convivía con una segunda televisión, en este caso de carácter comercial, la Independent Television (ITV).

Si en los países más autoritarios la apertura de los nuevos canales era una decisión interna del Gobierno que anunciaba el ministro de turno, en los sistemas parlamentarios era necesario un cierto debate público, lo que permite un mejor examen de los motivos que llevaron a la creación de los segundos canales. El Parlamento británico, por ejemplo, creó en 1960 el Comité Pilkington para evaluar la labor tanto de la BBC como de la privada ITV y examinar la posibilidad de otorgar otro canal a una o a ambas, para lo que valoró informes de instituciones y opiniones de expertos. Así, Hugh Greene, director de la BBC entre 1960 y 196924, defendía la creación de un segundo canal público y apuntaba que el motivo por el que debía dársele luz verde era que «no sentían que estuvieran haciendo su trabajo apropiadamente solo con un canal». Kenneth Adam, jefe de televisión en la corporación, lo explicaba así:

In the circumstances of a single channel we cannot fulfill what the Charter lays upon us to do. We do not inform enough; we do not educate enough; the chance of experiment so that we may entertain better is very limited ${ }^{25}$.

El informe oficial de la propia BBC apuntaba en la misma línea: tener «muchas más oportunidades para programas de naturaleza experimental ${ }^{26}$. Pero también se ofrecieron otros motivos al Comité para aprobar la segunda cadena. Greene exponía que BBC-2 estaba planeada como una emisora que ofreciera «al-

${ }^{23}$ Noam, 199I, pp. 73 y ss. En un primer momento, se barajó la posibilidad de que fuera una agrupación de los magnates de la prensa quien la gestionara, en lugar de los länder.

${ }^{24}$ Sobre la gestión de Greene al frente de la BBC, que optó por la innovación y el reflejo de una sociedad en cambio, así como nuevos géneros, como la sátira política, como forma de mantener el liderazgo frente a la recientemente creada televisión privada ITV, Briggs, y Burke, 2002, pp. 238 y ss.

25 Adam, 1961: «Con un solo canal no podemos cumplir con las tareas que nos encomienda la Cédula Real (Royal Charter). No informamos lo suficiente; no educamos lo suficiente; las posibilidades de experimentar para poder mejorar nuestra capacidad de entretener son muy limitadas».

26 BBC Memorandum n I, presentado en agosto de 1960, Report of the Committee of Broadcasting, 1960, Apéndice E, p. 89, citado en Briggs, 1995b, p. 403. 
ternativas razonables», incluido un espacio mucho mayor para los aspectos regionales y la cultura (education) en el más amplio sentido de la palabra, aspectos ambos que, junto a la experimentación, también serían fundamentales en la futura la Segunda Cadena, si bien se desarrollarían más adelante. Así, en la inauguración de la cadena española la prensa insistía sobre todo en su carácter cultural y en tratarse de una alternativa con programas originales «para quienes prefieran un buen concierto en lugar del partido de fútbol de turno» ${ }^{27}$, y, sobre todo, como un logro técnico que pondría a España a la misma altura que otros países europeos; pero la reflexión acerca de cómo debía ser ese canal era escasa: iqué tipo de alternativa y para quién? Más allá de los discursos oficiales sobre el carácter «diferente» de la cadena, lo cierto es que estas cuestiones fundamentales se resolvieron por la vía de la práctica diaria.

Esta labor recayó sobre los hombros de Salvador Pons, un funcionario del Ministerio de Información y Turismo que en 1966 había sido encargado de realizar una serie para dar a conocer España a los propios españoles. Se trataba de Conozca usted España - emitida inicialmente en la Primera Cadena, pero repetida después en el UHF-, y que fue seminal por varias cuestiones. En primer lugar, el propio Pons fue nombrado director in pectore de TVE-2, incluso antes del comienzo oficial de las emisiones ${ }^{28}$.

En segundo lugar, se asentó un sistema de producción propio, que daría lugar a muchos contenidos con una similar línea etnográfica, y que, ante la escasez de recursos, fueron encargados no a personal de TVE, sino a jóvenes egresados de la Escuela Oficial de Cinematografía, como Ramón Masats, César Fernández Ardavín, Jesús Fernández Santos, Claudio Guerín, Pedro Olea, Mario Camús o Pío Caro Baroja, así como a miembros de compañías de teatro universitario experimental, como el grupo TEU, y que posteriormente pasarían en bloque a formar el personal propio de la Segunda Cadena ${ }^{29}$.

Finalmente, esto marcaría el carácter de la programación de la Segunda Cadena, que, desde un proyecto inicial que se reducía a ser «diferente» de la Primera, se configuró como un canal eminentemente cultural. Así lo recuerda uno de los protagonistas, Pío Caro Baroja:

\footnotetext{
${ }^{27} A B C, 21$ de septiembre de 1966, p. 42.

28 «Aunque su programación autónoma se estrenó oficialmente el 15 de noviembre de 1966, la Segunda Cadena comenzó a tener vida propia - y a dibujar su personalidad - a partir del 20 de julio de ese mismo año, fecha en que se produjo, como se ha dicho, el nombramiento de su director, Salvador Pons», Munsó Cabús, 200I, p. 91.

29 Hernández Corchete, 2008, p. 94.
} 
el programa gustó, y Fraga decidió pasar aquella producción incipiente a Prado del Rey, y que [Salvador Pons] se hiciera cargo de la Segunda Cadena, dándole a esta un carácter cultural [...] Pasamos a ocupar toda una segunda planta de Prado del Rey, cuyo personal [...] nos recibió de uñas tildándonos de «rojeras» ${ }^{30}$.

Por su parte, la cadena británica también tenía un marcado carácter minoritario, como recalcaba Kenneth Adam, señalando que BBC-2 se dirigiría a «aquellas personas que están interesadas en programas diferentes (in the uncommon denominators) ${ }^{\prime 3}$. No obstante, como en el caso de su contrapartida española, el énfasis en lo cultural debía tratarse más del espíritu que animara a la cadena que de una sobreespecialización que a la postre resultara demasiado restrictiva. En su alocución, Greene alertaba al Comité Pilkington de la necesidad de evitar hacer un canal «específicamente cultural», puesto que ello solo serviría para que el resto de televisiones se sintieran legitimadas para poder obviar la divulgación en su programación ${ }^{32}$. Ante estos argumentos, el Comité Pilkington aprobó sin reparos la concesión de otro canal para la $\mathrm{BBC}$, pero rechazó otorgar un segundo canal a la ITV «en ningún futuro próximo» ${ }^{33}$.

A la hora de ejecutar el proyecto, y pese a los años de diferencia entre las distintas cadenas, se tomaron una serie de decisiones técnicas comunes. La más importante de ellas fue utilizar la Ultra-High Frequency, o UHF, a diferencia de las primeras cadenas, que emitían en Very-High Frequency, o VHF. Los motivos fueron un mejor reparto del espectro de onda, que debía alojar tanto a la televisión como a las radios -y que, en algunos países, como en Portugal, estaba saturado-y, no en menor medida, que la emisión en 625 líneas a través de UHF abría la puerta para la televisión en color, un proyecto muy atractivo.

La primera consecuencia de esto fue que se hizo necesario construir una infraestructura nueva prácticamente desde cero, partiendo de la capital y extendiéndose hacia las ciudades más importantes. Pero aquí ya empezaron a aparecer diferencias en la inversión que cada gobierno estaba dispuesto a hacer para la instalación y expansión inicial de las cadenas.

En Portugal la RTP tuvo un comienzo modesto. Al inicio de las emisiones, el 25 de diciembre de 1968, solamente estaba en funcionamiento el emisor de UHF de Lisboa. La operación fue complicada, pues fue necesario trabajar para

\footnotetext{
${ }^{30}$ Caro Baroja, 2002, pp. 147-148.

31 Briggs, 1995b, p. 402.

32 «We are anxious to have an additional programme because we don't think we are doing our job properly without it [...] The programmes would be planned together to provide reasonable alternatives. There would be much more space for regional contributions and for educational material in the widest sense of the word»». Address to the Bow Group, Pilkington Committee, 29 de septiembre de 1960 (R44/548), citado en Briggs, 1995b, pp. 402-403.

33 «At any rate for the time being», Silvery, 1974, p. 202.
} 
modificar un centro emisor ya existente, aumentando el número de antenas, lo que implicó elevar en veinte metros la torre, y reforzarla para soportar más de siete toneladas extra. En años posteriores se fue expandiendo la red con nuevos centros emisores en otros puntos del país, pero en un clima dominado por la incertidumbre, pues no había decisiones claras. Todos los centros, por ejemplo, estaban preparados para emitir en color, ya fuera en sistema PAL o en sistema SECAM, pero la ausencia de una decisión oficial sobre el estándar a adoptar retrasó la puesta en marcha de la televisión en color $^{34}$. Algo muy similar estaba ocurriendo en España, que se veía dividida entre un sistema PAL que estaba siendo adoptado en la mayoría de Europa y el sistema SECAM, minoritario pero instalado en un país tan destacado como Francia, por el que pasaba el enlace a Eurovisión ${ }^{35}$. Igualmente fue complicado el encontrar un lugar desde el que emitir. En Portugal, los estudios Lumiar, que estaban siendo construidos para sustituir al ya obsoleto estudio B, tuvieron que ser adaptados para servir a ambos canales. La empresa no estuvo exenta de dificultades, habida cuenta de que solo contaba con 38 metros cuadrados y dos cámaras para ambos canales. La señal procedente de los estudios debía ser más tarde procesada, junto a la de las conexiones exteriores y las grabadas (videotapes, etc.) para su emisión separada en dos canales ${ }^{36}$. La Segunda Cadena, por su parte, no pasaba tales apreturas, pues compartía con TVE-I los estudios de Prado del Rey, inaugurados en 1964, y algunos programas grabados en el estudio de Miramar, en Barcelona. Los de Prado del Rey en particular eran un dechado de recursos, con más de 1200 metros cuadrados y los medios más modernos de la época ${ }^{37}$.

Pero si un gobierno se volcó con la puesta en marcha de su segunda cadena fue el británico. Para iniciar las emisiones de BBC-2 fue necesario un proyecto conjunto entre la BBC, la Post Office - que controlaba los enlaces de microondas, necesarios para unir los estudios y los transmisores- y el sector privado. Fue necesario construir un nuevo transmisor en el centro de Crystal Palace, así como una cadena de 12 emisoras de alta potencia y unos 40 repetidores de menor potencia, y eso solo para el área de Londres. La empresa tuvo una dificultad añadida: los plazos se adelantaron varias veces, hasta pasar de una inauguración prevista en abril de 1965 a la final, en abril de 1964, dos años después de la autorización del Comité Pilkington ${ }^{38}$. En palabras de Leonard Miall,

\footnotetext{
${ }^{34}$ Hogan Teves, 2007.

${ }^{35}$ Faus Belau, 1995, pp. 256 y ss.

${ }^{36}$ Hogan Teves, 2007.

37 Martín Quevedo, 2015.

${ }^{38}$ Briggs, 1995b, pp. 405-406.
} 
Es como tener que construir una segunda red de ferrocarril nacional, una que gradualmente llegue a todas las estaciones de tren existentes, pero en la que el ancho de vía sea diferente. $Y$, más aún, tenemos que continuar haciendo funcionar el antiguo sistema, con el antiguo ancho de vía, durante un número de años indeterminado, a pesar de que algunas de las locomotoras $y$ vagones deben ser capaces de viajar por cualquiera de las dos vías indistintamente ${ }^{39}$.

Miall, que había sido nombrado director adjunto (assistant director) de la $B B C$ en 196I, fue el encargado de poner en marcha BBC-2. Por sus servicios recibió la Orden del Imperio Británico, lo que muestra la importancia que el Estado dio a este proyecto. Los esfuerzos y el interés de la BBC en la puesta en marcha de la infraestructura para emitir en UHF trascendían el segundo canal; se trataba sobre todo de preparar las emisiones en color.

La Segunda Cadena de TVE tuvo un comienzo muy potente, más cercano a la BBC-2 que a la RTP2. Empezó emitiendo solo en Madrid durante las emisiones en pruebas, y más de un año antes de su inauguración, en septiembre de 1965, se extendió a Zaragoza y Barcelona ${ }^{40}$. Sin embargo, en los tres años siguientes, hasta 1969 , la cobertura se extendió hasta el $30 \%$ del territorio español, pero allí se detuvo. Los motivos de la paralización se atribuían a «las dificultades que crea la particular orografía española» ${ }^{41}$, pero cabría buscar la causa más bien en las dificultades económicas que atravesaba Televisión Española y que impidieron que los ambiciosos planes que se trazaban en el discurso oficial se llevaran a cabo, tanto en la extensión de la cobertura de la red de UHF como en la llegada de la televisión en color. Frente a eso, RTP-2 cubría la mitad de Portugal, aunque es cierto que tanto por topografía como por extensión este objetivo era más fácil de conseguir en el país luso ${ }^{42}$.

2.2. El eje programático: la creación de una identidad de las segundas cadenas

Lo más complicado de la puesta en marcha de las segundas cadenas fue, sin duda, el darles una programación apropiada. Como se ha visto, la propuesta de la BBC-2 pasaba por una programación complementaria a la primera cadena, pero con un énfasis particular en lo minoritario, y lo mismo ocurrió en el modelo estatalista. Así, por ejemplo, el director General adjunto de la Radio y Televisao de Portugal, Matos Correia prometía en la emisión inaugural:

\footnotetext{
${ }^{39}$ Traducción propia. Miall, L. «The Future of BBC Television: A Lecture by Leonard Miall, who is Organizing the Planning of the BBC's Second Television of a Series of Lunch-time Lectures in the Concert Hall at Broadcasting House», en British Broadcasting Television Lunchtime Lectures, I, p. 5, citado en Briggs, 1995b, p. 405.

40 Historia de TVE, 1986, p. 49.

${ }^{41}$ La Vanguardia, 23 de marzo de 1974, pp. 33.

42 Noam, 1991, p. 252.
} 


\begin{abstract}
La Segunda Cadena, que ha entrado en su fase experimental, tiene como objetivo fundamental -en un futuro que esperamos sea cercano- proporcionar a los señores espectadores una programación complementaria de la ya existente, o de naturaleza diferente, entre lo emitido en el primer y el segundo canal. Se procurará ofrecer la posibilidad de escoger entre géneros diferentes, con la preocupación de lograr un equilibrio que permita una oferta coherente con las preferencias de cada cual, o la presentación de determinadas emisiones que, por su naturaleza experimental o demasiado especializada, no tendrían razón de ser justificadas si existiera un solo canal ${ }^{43}$.
\end{abstract}

Sin embargo, la carestía material obligó a que la RTP tuviera que recurrir durante las emisiones experimentales de su segunda cadena a repetir la programación de la primera a distintas horas, de modo que la buscada complementariedad se limitó simplemente a ofrecer un horario alternativo para recuperar aquellos programas grabados que no se hubieran podido ver en su momento.

Lo mismo ocurrió en España cuando se puso en marcha la Segunda Cadena. Sin embargo, la cadena española gozó de una programación enteramente original desde el momento de su inauguración oficial, mientras que el proceso en Portugal fue más paulatino, recurriéndose durante más tiempo a series filmadas y programas grabados: en 1969 se emitieron 1012 horas, y 889 al año siguiente, todas de programación repetida. Hasta la inauguración de los repetidores de Oporto y Montejunto en 1970 la cobertura se limitó a la propia Lisboa ${ }^{44}$.

No obstante, el carácter cultural de la Segunda Cadena se manifestaría principalmente en el espíritu con el que se seleccionaban los programas, aunque el macrogénero que prevaleció durante toda la etapa fue el de entretenimiento y no el de divulgación, como cabría pensar ${ }^{45}$. En conjunto, se trató de una programación innovadora, alejada de los estereotipos que se venían construyendo en TVE. Programas como Cineclub, que emitía ciclos de cine independiente y nunca antes visto en España en versión original, incluyendo ciclos de películas procedentes de países comunistas; Cuestión urgente, un programa de documentales de problemas actuales como el alcoholismo juvenil o las madres solteras, «narrados por las víctimas y completado con especialistas» ${ }^{46}$; o, sobre todo, Estudio abierto, que rompió todos los moldes formales, estéticos y temáticos de lo que debería de ser un programa y un presentador, y que son, en ocasiones, difíciles de adscribir a un solo género.

\footnotetext{
43 Traducción propia. Hogan Teves, 2007.

${ }^{44}$ Hogan Teves, 2007, p. 5.

45 Martín Quevedo, 2015, p. 49.

46 «Habla el padre Martínez Roura, director del programa Cuestión urgente», Tele-Radio, núm. 636, 2-8 marzo 1970, p. 29.
} 
El punto de inflexión para RTP-2 fue el año 1971. La programación se amplió en una hora diaria, empezando las emisiones a las 20.30 , lo que permitió alcanzar las 1233 horas emitidas al final del año, y se inauguraron los centros emisores de Lousã y Muro para el centro y norte del país. Pero el cambio fundamental tuvo lugar cuando se resolvió el problema que tenía paralizada la programación independiente de RTP-2: la falta de recursos. Tras mostrarse incapaz de financiarse por sí misma o a través de la publicidad, la Radio e Televisão de Portugal decidió hacer un concurso público para la concesión de los espacios publicitarios de la segunda cadena. La empresa beneficiaria fue Movierecord Portuguesa, que ya tenía la licencia de los espacios del primer canal ${ }^{47}$. Después de aquello, con más recursos liberados para la continuación de los planes de expansión de la infraestructura, se logró en 1972 que RTP-2 llegara al 50\% del Portugal europeo ${ }^{48}$.

La llegada de Movierecord supuso el comienzo de la programación independiente, pero no el fin de las dificultades económicas, agudizadas por la escasa cobertura de la cadena - aunque mucho mayor que su homóloga española-, lo que dificultaba la contratación de publicidad. Poco a poco, y principalmente a partir de 1973, se fue aumentando el porcentaje de programación original en las parrillas de RTP-2. Esta tuvo algunas similitudes con la de otras cadenas europeas, y con la Segunda Cadena en particular, tanto en la temática como en los formatos de sus principales espacios: la retransmisión de conciertos de música culta, con programas como Noites de Ópera -muy similar al español Teatro Real-; la dramatización de obras de autores célebres - Antologia en su versión portuguesa, Escritores en televisión en la española-, y, por supuesto, las teleseries extranjeras $^{49}$.

La crónica carestía en RTP-2 propició una situación en que esta vivió hasta finales de los años setenta a la sombra del primer canal, tanto en lo económico - sus presupuestos salían de lo que sobraba del primer canal- como en lo programático. Géneros que en la televisión española fueron fundamentales quedaron en Portugal confinados al primer canal, como los programas divulgativos del paisaje y la cultura del país - A terra, o mar e a Gente, similar a Conozca Usted España - Fiesta, salvando las distancias-, el teatro televisado, que nunca gozó de demasiada presencia en la televisión portuguesa, o el cine.

No obstante, la televisión portuguesa experimentó un mayor desarrollo en el ámbito informativo, no tanto en los telediarios - dado que mantener dos telediarios independientes estaba fuera de las posibilidades de la RTP, se recurría

\footnotetext{
${ }^{47}$ Hogan Teves, 2007, p. 24.

${ }^{48}$ Hogan Teves, 2007, p. 8.

49 Hogan Teves, 2007, p. 10.
} 
a la emisión simultánea en ambas cadenas de este- como en los programas de actualidad o current affairs, que a menudo exploraban las fronteras de lo que se podía decir en una dictadura, como Zip. Paradójicamente, fue también el momento de mayor censura, desde la llegada de Ramiro Valadão a la presidencia de la RTP. Valadão acabó cerrando Zip, pero este quedó como un hito fundamental de la televisión portuguesa.

La carencia de medios no fue, sin embargo, el problema de la BBC-2, sino más bien la dificultad de articular una programación capaz de cumplir los objetivos propuestos de ser una alternativa tanto a BBC-I como a la ITV, y hacerlo además de manera innovadora. El primer director de la segunda cadena británica, Michael Peacock, diseñó una parrilla inicial denominada "patrón de siete caras» (seven faces pattern), en el cual cada día de la semana tenía un «tema» alrededor del cual se articulaban todos los programas.

Así, el lunes era el día del entretenimiento familiar, basado en comedias; el martes era el día de la divulgación; el miércoles se emitía una selección de los mejores programas de BBC-I y 2; el jueves la programación se centraba en las minorías, con un énfasis especial en los deportes minoritarios; el viernes era otro día de entretenimiento familiar, aunque esta vez basado en el drama; los sábados se ofrecía una alternativa a los programas deportivos que en ese momento ocupaban BBC-I; y, por último, los domingos estaban divididos en dos: en la primera mitad se intentaba «crear la sensación de una ocasión importante» con música y teatro serios alternados con filmes europeos, mientras que en la segunda mitad se ofrecía un programa de entretenimiento como alternativa a Monitor, el programa de current affairs que era el buque insignia de BBC-I ${ }^{50}$.

La práctica de dividir el día en dos mitades era habitual en el modelo de Peacock: cada día se emitirín unos informativos propios — que, además, estaban más centrados en la información de trasfondo que en la actualidad-, seguidos de un programa «de contraste» con el tema del día: jazz los miércoles, un informativo sobre la actualidad parlamentaria los viernes o un sumario de las noticias de la semana para sordomudos los domingos.

Peacock intentó combinar esta parrilla innovadora con una selección de programas que huía del cliché de televisión cultural sin descuidar la calidad. Teleseries como Arresto y juicio - también emitida en la Segunda Cadena- o programas como Let Me Speak, que daba voz a jóvenes con opiniones minoritarias o sorprendentes, tenían un hueco junto a programas de altísimo presupuesto, como The Great War, una serie documental sobre la Primera Guerra Mundial formada por veintiséis episodios de cuarenta minutos cada uno, y que llegó a

50 Briggs, 1995b. 
usar, entre otras fuentes, los testimonios de 35000 participantes en la guerra, un proyecto incomparablemente mayor que cualquier cosa que se hubiera hecho o se estuviera haciendo en la televisión española o la portuguesa.

En conjunto, a pesar del intento de diversificar la programación, esta tuvo un aire propio, más sosegado e intelectual que lo que se emitía en BBC-I. Sin ser «programas selectos, tampoco estaban creados para ganar la batalla por las audiencias $»^{51}$.

Sin embargo, el «patrón de las siete caras» no sobrevivió demasiado, y fue abandonado apenas unos meses después del comienzo de las emisiones regulares, en julio de 1964. Los motivos fueron varios. En primer lugar, lograr una complementariedad real entre las programaciones de BBC-I y BBC-2 se probó como una tarea difícil, cuando no imposible. De la misma manera que en España coincidieron durante un tiempo programas tan populares como Estudio uno en TVE-I y Estudio abierto en la Segunda Cadena, en la BBC resultaba complicado evitar situaciones en que o bien el espectador se viera forzado a elegir entre dos programas muy atractivos en una misma franja, o bien una de las dos cadenas concentrara abrumadoramente la audiencia en detrimento de la otra.

En segundo lugar, también resultó complicado hacer coincidir las horas de inicio y finalización de los programas de ambas cadenas, de modo que los espectadores tuvieran la opción de cambiar entre una y otra fácilmente al término de cada emisión. Por último, se recurrió a concentrar los programas más potentes de la BBC-2 en una sola noche a la semana, lo cual impulsaba a los espectadores a creer que la cadena tenía interés solo en ese día, y que podían ignorarla durante el resto de la semana en la seguridad de que no se emitiría nada que valiera la pena ${ }^{52}$.

La búsqueda de una programación propia continuó durante los años siguientes, pero la pobre acogida de la segunda cadena británica a pesar de los recursos invertidos y la inestabilidad política de los cargos directivos hicieron que hubiera que esperar a la llegada de un nuevo jefe de programas para que BBC-2 encontrara su identidad. David Attenborough se convirtió en director de la cadena en 1965, desde donde dirigió el cambio en la programación y algunos de los hitos más destacados de la misma, como el comienzo de las emisiones en color en 1967.

Attenborough fue capaz de renovar toda la programación de la segunda cadena, apostando por programas innovadores y de calidad que marcarían la identidad de la cadena en los años venideros. Por ejemplo, The Money Programme

\footnotetext{
${ }^{51}$ Crisell, 1997, pp. I19-120.
}

52 Briggs, 1995b, pp. 408-4I3. 
era un espacio de actualidad económica, pero con una óptica diferente. Pretendía abordar

los problemas prácticos de fabricar y vender productos, biografías de empresarios, el drama y la estrategia de las luchas de poder en las empresas, técnicas y problemas de la modernización, la banca en la Bolsa londinense, las relaciones entre la política y el mundo de las finanzas, etc. ${ }^{53}$,

todo ello con invitados de primerísimo nivel como el presidente del FMI, el Primer Ministro francés o el gobernador del Banco de Inglaterra. Junto a ellos hubo programas de entretenimiento arriesgados e innovadores, como el humor surrealista de Monty Python's Flying Circus o The Old Grey Whistle Test, un programa de música moderna con actuaciones en directo, pero desde un punto de vista alejado de mitificaciones. También hubo lugar para programas de entretenimiento más tradicional, pero sumamente exitoso, como The Forsyte Saga — La saga de los Forsyte en España-, un drama de alto presupuesto que cosechó éxito de crítico y público en toda Europa ${ }^{54}$.

En 1969 Attenborough, cuya gestión era universalmente alabada, se convirtió en director de programas de ambas cadenas, para ser sucedido por Robin Scott al frente de BBC-2. Pero la marcha de Attenborough también supuso el inicio de las dificultades para la cadena. Los problemas económicos empezaron a agudizarse en toda la corporación, hasta el punto de que las desconexiones regionales que ya estaban planificadas fueron canceladas por falta de fondos, y a la altura de 1974 BBC-2 se vio obligada a reducir su horario de emisión en tres horas diarias de lunes a viernes.

Ello supuso, como es lógico, una merma sustancial en la calidad de la programación, porque la oferta se redujo fundamentalmente a grabaciones, redifusiones y programas de bajo presupuesto ${ }^{55}$. Lo mismo le ocurrió a TVE, que a la muerte de Franco se encontraba al borde de la bancarrota. La crisis internacional tuvo un impacto transversal en todas las televisiones: tanto aquellas que no habían llegado a despegar, como RTP-2, como las aparentemente consolidadas como $B B C-2$ sufrieron graves recortes.

53 Attenborough en BBC-2 Current Affairs Programmes, citado en Briggs, 1995b, p. 583.

54 Tal fue su éxito que llegó a emitirse incluso en las televisiones de la URSS, notoriamente reacias a incorporar producciones occidentales a sus parrillas, Wasserstein, 2007.

55 No obstante, hay que señalar que la pérdida de peso de los programas en directo frente a las grabaciones en magnetoscopio era un movimiento internacional desde mediados de los 60 , ocasionado en parte por el abaratamiento de la tecnología y la simplificación de los procesos de producción de programas, y por la extensión de un mercado internacional de contenidos. Por ejemplo, a la altura de 1969-70, la media de programas grabados era del $49 \%$ en las televisiones estadounidenses y del $40 \%$ en las europeas frente a un $14 \%$ de espacios en directo. Faus Belau, 1995, pp. 259 y ss. 


\subsection{El eje de la recepción: buscando al «público» en «servicio público»}

A pesar de las diferencias que se han visto, las segundas cadenas compartieron un problema común: la dificultad para atraer una porción significativa de la audiencia. Es complicado concretar cifras, pues en los años 60 y 70 la medición de audiencias era muy rudimentaria en Europa ${ }^{56}$. Si bien es cierto que hubo un crecimiento en el número tanto de receptores como de antenas, como se ha señalado ${ }^{57}$, es difícil saber cuántos de estos televisores podían recibir el UHF, puesto que solo los de nueva fabricación tenían integrada esta función. Para los anteriores era necesario comprar un adaptador.

En cualquier caso, la mayoría de cadenas tenían departamentos dedicados a la evaluación del éxito que tenían los programas entre los espectadores, pero en los países en los que existían solo cadenas públicas -es decir, todos menos Reino Unido- estos sondeos solían enfocarse en la aprobación que cada programa tenía para los encuestados, más que en el número de espectadores. Más aún, la mayoría de estos estudios eran realizados para la cadena y no se hicieron públicos, salvo parcialmente, y no en todos los casos. Una vez más, los datos más fiables son los de la BBC, cuyo Departamento de Investigación de Audiencias databa de antes de la Segunda Guerra Mundial ${ }^{58}$.

Buena parte de la responsabilidad de esas dificultades de despegue de las segundas cadenas se debió a razones de índole técnica. La mayoría no tuvo una cobertura nacional hasta al menos dos décadas después de su inauguración, por la necesidad de crear una red de UHF partiendo desde cero. La solución por la que se optó en todos los casos fue empezar por la capital, y extender la red a las mayores ciudades a medida que los recursos lo permitían. Ello lógicamente derivaba en una mayor dificultad para obtener financiación, pues los directivos tendían a privilegiar una cadena de alcance nacional antes que una cuya audiencia estaba fragmentada y que, por lo tanto, ofrecería un menor retorno social por las inversiones.

Más aún, a esto había que añadir una dificultad adicional: incluso en aquellas zonas en que llegaba la señal de la segunda cadena, era necesario adaptar el receptor o comprar uno nuevo con capacidad para el UHF. Había dos motivos por los que los espectadores de estas zonas podían mostrarse indecisos a la hora de dar el paso: el desconocimiento de que con un adaptador podrían ver otro canal, y la renuencia a realizar un gasto adicional. En todos los casos se llevaron a cabo

\footnotetext{
${ }^{56}$ En parte, esto derivaba de que la televisión era una gran novedad en muchos países (ver nota I).

57 En España, por ejemplo, se pasó de unos 250000 televisores en 1960 a unos 5800000 en 1970 (Ruiz Carnicer, 2004, p. 297). Una evolución similar había experimentado la radio en España la década anterior, Gómez García y Cabeza, 2013, pp. 127-128. 58 Silvey, 1974.
} 
campañas gubernamentales para dar a conocer la segunda cadena de turno desde antes del comienzo de las emisiones regulares, en algunos casos con más éxito que en otros.

El Departamento de Investigación de Audiencias de la BBC estimaba, por ejemplo, que en el primer año de emisión de BBC- 2 solamente un $3 \%$ de los poseedores de un aparato de televisión estaban equipados para recibirla ${ }^{59}$. La cifra creció lentamente en los años siguientes, pero el gran impulso llegó con el comienzo de las emisiones en color en 1967. Ese año el número de televisores capaces de sintonizar UHF casi se duplicó respecto al año anterior, del $13 \%$ en 1966 al $25 \%$ en 1967. La tendencia continuó en los años siguientes: $34 \%$ en 1968, y $45 \%$ en 1969, aunque habría que esperar hasta bien entrados los setenta para que muchos de estos espectadores pudieran hacerse con una televisión en color. Y probablemente este crecimiento en la audiencia potencial se debía más a la compra de nuevos televisores, capaces no solo de recibir el segundo canal, sino también de reproducir la imagen en color.

Sin embargo, ni la readaptación del parque televisivo británico ni la expansión de la red de UHF influyeron sustancialmente en la aceptación por parte de la audiencia de la segunda cadena. Durante toda la década de los sesenta y principios de los setenta el porcentaje del tiempo que le dedicaban los espectadores durante las horas en que emitía se mantuvo alrededor del 10\%, con repuntes regulares de hasta el $13 \%$ y bajadas al $8 \%^{60}$. Incluso esas cifras resultan poco fiables, en la medida en que, como los expertos de la propia BBC no dejaban de señalar, las primeras áreas a que llegó BBC-2 tenían una proporción mayor que el resto del país de clase alta y media-alta, precisamente el tipo de espectador al que se dirigía su programación, por lo que generalizar los porcentajes y extrapolarlos a lo que ocurriría en el resto del país era, cuanto menos, arriesgado. Además, se tardó siete meses, desde el comienzo de las emisiones regulares, en empezar a ofrecer datos de audiencia, lo que motivó el malestar del Parlamento ${ }^{61}$.

Frente a eso, a la altura de 1969 Televisión Española estimaba el número de espectadores que veían alguna vez la Segunda Cadena en torno al 30\%, frente al casi $100 \%$ que veía la Primera. El dato de cuántos la conectaban todos los días es aun más explícito: el $60 \%$ elegían diariamente la Primera, mientras que menos del $5 \%$ prefería la Segunda. Estos datos cobran pleno sentido cuando se comprueba que la proporción de televidentes que podían ver la Segunda Cadena solo superaba el $50 \%$ de los espectadores en Madrid, Toledo, Ciudad Real, Zaragoza,

\footnotetext{
59 Silvey, 1974.

60 Silvey, 1974.

61 Briggs, 1995b, p. 4I3.
} 
Guadalajara y Barcelona. Entre el 30 y el $49 \%$ estaban Segovia, Valladolid, Palencia, Sevilla, Navarra, el País Vasco y toda Galicia excepto Ourense ${ }^{62}$.

Una vez más, los datos no son enteramente fiables, y en la medida en que TVE no explicaba la metodología de la investigación de la que se habían extraído, es difícil hacer comparaciones. Además, desde 1972, con Adolfo Suárez como director general de TVE, se elaboraba el Panel de Aceptación de programas que medía con una puntuación de I a 10 el grado de aprobación de algunos programas por parte de quienes eran sus espectadores, pero no daba cuenta de la cantidad de espectadores. Lo confeccionaba semanalmente el Servicio de Estudios de Contenidos y la prensa reflejaba sus resultados de cuando en cuando. En la medida en que partía de la premisa de que debían votarse solo aquellos programas que se habían visto - lo que situaba en desventaja a la Segunda Cadena, por los motivos expuestos-, y que no había ningún criterio de representatividad en la muestra estudiada, resulta difícil hacer extrapolaciones. De los pocos programas de la Segunda Cadena que aparecían en los paneles, destacan los dedicados al cine, como Pantalla grande y Revista de cine, y los de información deportiva (EI mundo del deporte), algo que concuerda con el énfasis de la televisión franquista en usar las retransmisiones deportivas para exhibir los adelantos tecnológicos que iban incorporándose a TVE ${ }^{63}$.

Pero está claro que, a pesar de que la Segunda Cadena era sin duda un canal minoritario, que gozó de muchísimos menos medios humanos y materiales que BBC-2 - aunque muchos más que RTP-2-, su audiencia era al menos igual, y probablemente superior en términos relativos, a la cadena británica entre aquellos que podían verla. Las dificultades económicas de España en general y de TVE en particular desde finales de la década de los sesenta, empero, influyeron en que durante mucho tiempo los espectadores que tuvieron acceso a la Segunda Cadena constituyeron una minoría localizada solo en las grandes urbes y zonas aledañas, algo tanto más importante por cuanto la sociedad española era menos homogénea que la británica, en particular en lo tocante a las diferencias entre campo y ciudad.

\section{CONCLUSIONES}

En definitiva, las segundas cadenas se enfrentaron, independientemente del modelo al que pertenecieran, a una serie de dificultades comunes, derivadas del panorama audiovisual internacional: una tendencia a desdibujar las particularida-

\footnotetext{
62 Ministerio de Información y Turismo, 1969, pp. 12 y 14.

${ }^{63}$ Bonaut, 2009.
} 
des nacionales en cuanto a contenidos, la falta de acuerdo en los estándares tecnológicos, que retrasaron la puesta en marcha de la televisión en color varios años con respecto a Estados Unidos, y una situación económica que ya no era $\tan$ boyante como en los años 60, y que obligaba a replantear las prioridades de los diversos estados.

Además, es sintomático que, aunque en cada uno de los tres países analizados la segunda cadena se enmarcó en una estructura de la comunicación muy diferente - por ejemplo, marcada por la presencia o ausencia de competición privada, o la financiación a través de un canon o de publicidad-, el resultado fue similar: en todos los casos la alternativa que suponía la segunda cadena no logró aglutinar una audiencia sustancial, lo que agravó las dificultades financieras, políticas -en tanto que era difícil lograr la concesión de más recursos públicos sin el respaldo de los espectadores- y organizativas - la inestabilidad de los directivos al frente de las cadenas-.

Este fracaso relativo tuvo muchas causas. Por una parte, tecnológica, pues en los tres casos la cobertura nacional no se alcanzó hasta después del periodo estudiado. Además, y más allá del territorio en el que se recibían las emisiones, estaba la dificultad añadida de convencer a los espectadores de que compraran el necesario adaptador para poder sintonizar la cadena. Sobre este punto, es sintomático que solo la $\mathrm{BBC}$ emprendiera campañas informativas para asegurarse de que la población conociera esta posibilidad y se animara a hacerlo, e incluso así, su éxito fue muy limitado.

Por otro lado, en los tres casos la programación se planteó siempre como un apoyo y una alternativa a la primera cadena, para la que quedaban reservados los programas más exitosos. Así, tanto en Reino Unido como en Portugal y en España, la programación pretendió dirigirse a las minorías, especialmente a las más educadas, con unos espacios que enfatizaban lo cultural y lo experimental. A ello hay que añadir que apenas hubo tiempo de formar una cultura televisiva alternativa a lo que ya existía, precisamente por la mencionada inestabilidad organizativa, que llevó a dar bandazos con la programación, como ocurrió con la reducción de las horas de emisión en $\mathrm{BBC}$ o la repetición de contenidos del primer programa para ahorrar costes tanto en RTP2 como en TVE 2.

Finalmente, esto no significa que la situación de las tres cadenas fuera la misma. La apuesta que cada estado hizo por el proyecto de una segunda cadena, concretado en los recursos que se le dedicaron, produjo unos resultados muy diferentes. En el caso portugués, la absoluta carestía inicial se vio sucedida por una igualmente devastadora falta de interés gubernamental una vez que el canal se puso en marcha. El resultado fue que, aunque se intentaron hacer algunos espacios propios e innovadores, estos fueron escasos y de corta vida, pues en 
cuanto empezaron a tener repercusión y cuestionar el discurso oficialista, la censura acabó con ellos, como fue el caso de Zip. En el otro extremo, BBC2, pese a sus dificultades para aglutinar espectadores, sí logró poner en marcha espacios propios, creativos y que marcaron la televisión de aquellos años, como Monty Python's Flying Circus o las series documentales sobre las guerras mundiales, así como una programación propia y caracterizada por un alto grado de independencia respecto a $\mathrm{BBCl}$. El problema provino más, probablemente, de la falta de continuidad de las políticas de David Attenborough y del repentino recorte presupuestario de mediados de los años 70 .

Frente a estos dos casos, la Segunda Cadena de TVE se configuró, así, como un canal que tenía probablemente más en común con su homólogo portugués que con el ejemplo que suponía la BBC, pero que también logró aprovechar sus rasgos propios para conseguir un éxito que escapó a otras segundas cadenas. La Segunda Cadena consiguió hacer una televisión con tanta libertad como la BBC, pero con unos recursos a un nivel solo ligeramente superior al portugués. $Y$ más aún: esa libertad política y artística hizo posible que la programación de la Segunda Cadena, a menudo hecha por profesionales de otros ámbitos - el cine, el teatro, la política- alcanzara unas cotas de originalidad y calidad desconocidas en otras segundas cadenas hasta muchos años más tarde. Lo pequeño de la red española de UHF y la escasa voluntad de seguir ampliándola fue, paradójicamente, una bendición para el segundo canal, pues se vio libre de las expectativas de los directivos y los miembros del gobierno, y relegada al papel de un laboratorio donde probar programas experimentales sin mucho riesgo y con una libertad casi total. El mayor recurso de la Segunda Cadena fue, precisamente, no tener recursos.

\section{BiBLIOGRAFÍA}

Adam, K., «The Planning of Two-Channel Television», Ariel Supplement, octubre de 196I, pp. 12-15. Boddy, William, Fifties Television. The Industry and Its Critics, Urbana, University of Illinois Press, 1993.

Bonaut Iriarte, Joseba, Televisión y deporte. Origen y desarrollo histórico de la programación deportiva española (19561975), Buenos Aires, Libros en Red, 2009.

Briggs, Asa y Peter Burke, A Social History of the Media: from Gutenberg to the Internet, Cambridge, Polity Press, 2002.

Briggs, Asa, The History of Broadcasting in the United Kingdom: Volume I. The Birth of Broadcasting, Oxford, Oxford University Press, 196I.

Briggs, Asa, The History of Broadcasting in the United Kingdom: Volume II. The Golden Age of Wireless, Oxford, Oxford University Press, 1965.

Briggs, Asa, The History of Broadcasting in the United Kingdom: Volume III. The War of Words, Oxford, Oxford University Press, 1970.

Briggs, Asa, The History of Broadcasting in the United Kingdom: Volume IV. Sound and Vision, London, Oxford University Press, 1995a.

Briggs, Asa, The History of Broadcasting in the United Kingdom: Volume V. Competition, 1955-1974, London, Oxford University Press, 1995b.

Caro Baroja, Pío. Recuerdos de un documentalista. Historias de la vieja querida, Pamplona, Pamiela, 2002.

Craig, Allen, Eisenhower and the Mass Media. Peace, Prosperity and Prime-Time TV, Chapel Hill, The University of North Carolina, 1993. 
Crisell, Andrew, An Introductory History of British Broadcasting, London, Routledge, 1997.

Dobon-Roux, Pilar y Carlos Barrera, «Antena 3 Radio: nacimiento y primer desarrollo de una empresa periodística singular», Revista Internacional de Historia de la Comunicación, 4, I, 20I5, pp. I75-197.

Historia de TVE, Madrid, Diario Ya, 1986 [En línea]

Emanuel, Susan, La télévision et la culture en France: à la recherche d'une chaîne culturelle européenne (Doctoral dissertation, 1993, Rennes 2).

Ezcurra, Luis, Historia de la radiodifusión española. Los primeros años, Madrid, Editora Nacional, 1974.

Faus Belau, Ángel, La era audiovisual. Historia de los primeros cien años de la radio y la televisión, Barcelona, Ediciones Internacionales Universitarias, 1995

Fickers, Andreas. y Johnson, Catherine, «Transnational television history: a comparative approach: introduction», Media History, I6, I, 2010, pp. I-II.

Gómez García, Salvador y José Cabeza, «Oír la radio en España. Aproximación a las audiencias radiofónicas durante el primer franquismo (1939-1959)», Historia Crítica, 50, 2013, pp. 104-I31.

Gómez-García, Salvador, Juan Martín Quevedo y Raquel Quevedo-Redondo, «The Sound Portrait of a Dictator. A Study of Franco's Image in Radio Nacional de España», Media History, 202।, I- I4.

García Gil, Samuel, Salvador Gómez García e Itziar Reguero Sanz, «Espacios alternativos de libertad durante la Transición. Breve historia de las radios libres en España (1976-1983)», Revista Latina de Comunicación Social, 73, 2018, pp. II79-1210.

Hernández Corchete, Sira. La historia contada en televisión. El documental televisivo de divulgación histórica en España, Barcelona, Gedisa, 2008.

Hibberd, Matthew, «The Reform of Public Service Broadcasting in Italy», Media Culture Society, 3, 200I, pp. 233 252.

Hogan Teves, Vasco, RTP 50 Anos - História da Televisão em Portugal, 2007 [En línea].

Humanes, María Luisa y Martínez Nicolás, Manuel, «La cobertura de la política durante la Transición en los diarios El País y Abc», Periodística, 16, 2014-2015, pp. 79-89.

Jacobs, Jason, The Intimate Screen. Early British Television Drama, Oxford, Clarendon Press, 2000

Jeanneney, Jean-Noël (dir.), L'écho du siècle: dictionnaire historique de la radio et de la télévision en France, Paris, Hachette, 1999

Judt, Tony, Postguerra. Una historia de Europa desde 1945, Madrid, Taurus, 2016.

Levy, Mary Françoise, «Television, Family and Society in France 1949-1968», Historical Journal of Film, Radio and Television, 18, 2, 1998, pp. 199-212.

Lijphart, Arend, «Comparative Politics and the Comparative Method», American Political Science Review, 65, 3, 1971, pp. 682-693.

Maase, Kaspar, Diversión ilimitada. El auge de la cultura de masas (I850-1970), Madrid, Siglo XXI, 2016.

Manfredi Sánchez, Juan Luis, La televisión pública en Europa, Madrid, Fundación Autor, 2008.

Martín Quevedo, Juan, «Los programas informativos en la Segunda Cadena: proyectos y realidades (I966 1975)», Estudios sobre el mensaje periodístico, 20, 2014, pp. 73-89.

Martín Quevedo, Juan, La programación de la Segunda Cadena de TVE durante el franquismo (1966-1975), Madrid, Universidad Complutense de Madrid, 2015.

Martín Quevedo, Juan y Laura Fernández Ramírez, «Una propuesta metodológica para el análisis histórico de la programación en televisión. El ejemplo de la Segunda Cadena de TVE (I 966-| 975)», Revista Espacios, 4I, I2, 2020.

Martín Quevedo, Juan, Tamara Antona limeno y Nuria Navarro Sierra, «Contradicciones y veleidades en el debate parlamentario sobre la televisión pública en España (1990-2010)», Estudios sobre el mensaje periodístico, 26, 2, 2020, pp. 645-654.

Montero Díaz, Julio, Ángel Luis Rubio Moraga, Tamara Antona limeno, Juan Martín Quevedo y Laura Fernández Ramírez, «Los telediarios franquistas. Una investigación sobre las fuentes», Revista Latina de Comunicación Social, 69, 2014, pp. 9-24.

Montero Díaz, Julio (dir.), Una televisión con dos cadenas: la programación en España (1956-1990), Madrid, Cátedra, 2018.

Munsó Cabús, Joan, La otra cara de la televisión. 45 años de historia y política audiovisual, Barcelona, Flor del Viento, 2001 .

Noam, Eli, Television in Europe, New York, Oxford University Press, 1991.

Ortiz Sobrino, Miguel Ángel, y Nereida López Vidales, «Radiotelevisión Portuguesa (RTP) y Radiotelevisión Española (RTVE): dos caminos paralelos, dos destinos diferentes», Derecom, 9, 20I2, pp. I-I8. 
Palacio, Manuel, Una historia de la televisión en España. Arqueología y Modernidad, Madrid, Consorcio para la organización de Madrid capital de la cultura, 1992.

Palacio, Manuel, «Francisco Franco y la televisión», Archivos de la filmoteca: Revista de estudios históricos sobre la imagen, 42-43, 2, 2002, pp. 72-95

Peruško, Zrinjka y Antonija Čuvalo, «Comparing Socialist and Post-Socialist Television Culture. Fifty Years of Television in Croatia», VIEW Journal of European Television History and Culture, 3-5, 20I4, Pp. I3I-I50.

Potter, Jeremy, Independent Television in Britain: Volume III. Politics and Control, 1968-1980, London, Macmillan, 1989.

Potter, Jeremy, Independent Television in Britain: Volume IV. Companies and Programmes, 1968-1980. London, Macmillan 1990.

Reguero-Sanz, Itziar, Pablo Berdón-Prieto y Samuel García-Gil, «Evolución de la programación televisiva de debates y entrevistas ante la liberalización audiovisual en España (1980-20 I0)», Estudios sobre el Mensaje Periodístico, 26, 2, 2020, pp. 7I5-73I.

Rings, Werner. Historia de la televisión, Barcelona, Zeus, 1964

Rueda Laffond, José Carlos y Carlota Coronado Ruiz, «La codificación televisiva del franquismo: de la historia del entretenimiento a la historia como entretenimiento», Historia crítica, 10, 2010, pp. I70-195

Ruiz Carnicer, Miguel Ángel, «El sistema y la fabricación de un nuevo consenso», en La España de Franco (I 939 1975). Cultura y vida cotidiana, ed. Jordi Gracia Gracia y Miguel Ángel Ruiz Carnicer, Madrid, Síntesis, 2004, pp. 283-318.

Schulz, Wolfgang, «Public-Service Broadcasting in the Federal Republic of Germany», en Broadcasting Finance in Transition. A Comparative Handbook, ed. Jay G. Blumler y T. J. Nossiter, New York, Oxford University Press, 1991.

La audiencia de televisión en España, Madrid, Ministerio de Información y Turismo, 1969.

Sendall, Bernard, Independent Television in Britain. I. Origin and Foundation, 1946-1962, London, Macmillan, 1982.

Sendall, Bernard, Independent Television in Britain. 2. Expansion and Change, 1958-1968, London, Macmillan, 1983.

Silvey, Robert, Who's Listening? The Story of BBC Audience Research, London, George Allen \& Unwin, 1974

Spring, Joel, Educating the Consumer-citizen: A History of the Marriage of Schools, Advertising, and Media, Mahwah, Lawrence Erlbaum, 2003.

Syvertsen, Trine, Public Television in Transition: A Comparative and Historical Analysis of the BBC and the NRK, Leicester, University of Leicester, 1992.

Tracey, Michael, The Decline and Fall of Public Service Broadcasting, Oxford, Oxford University Press, 1998.

Wasserstein, Bernard, Barbarie y civilización. Una historia de la Europa de nuestro tiempo, Barcelona, Ariel, 2007.

Zamora Martínez, Patricia y Salomé Berrocal Gonzalo, «La figura del presentador de informativos: Un estudio durante el Régimen de Franco (1956-1975)», Estudios sobre el mensaje periodístico, 26, 2020, pp. 389 400 . 